
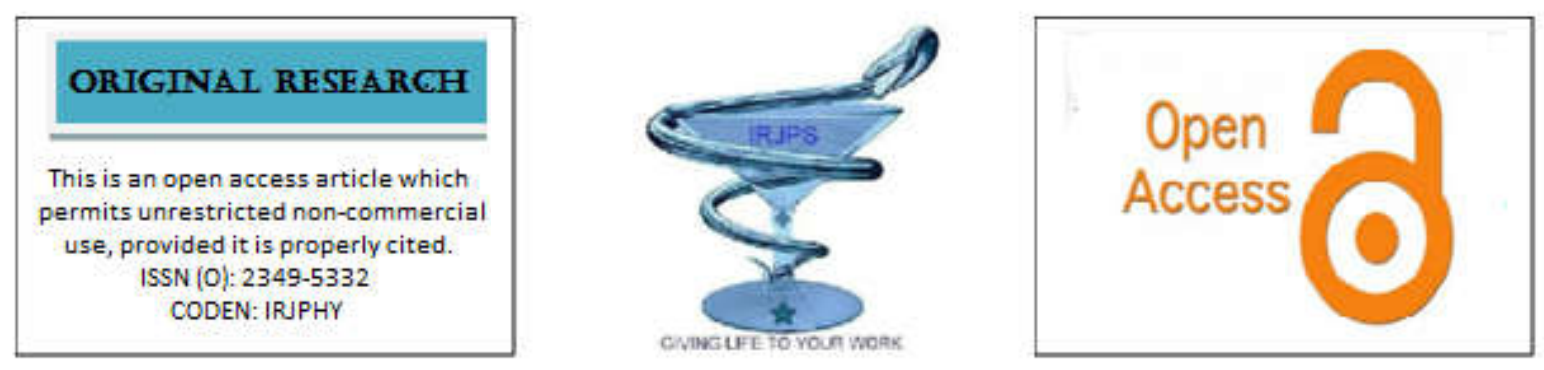

\title{
EVALUATION OF DRUG UTILISATION PATTERN IN GENERAL MEDICINE OUTPATIENT DEPARTMENT IN A TERTIARY CARE SETTING
}

\author{
Saba Khanum, Sushma Muchukota*, Al Kayum Ahmed, Karishma Parveen, Pooja, \\ Rashi L, Priyanka Dey, Yousuf Ahmed, Rinkumathappan
}

Department of Pharmacy Practice, Gautham College of Pharmacy, Bangalore, Karnataka, India

Submitted on: 20.04.2020;

\section{ABSTRACT:}

Background: WHO defined Drug utilization research as marketing, distribution, prescription and use of drugs in a society, with special emphasis on the resulting medical, social and economic consequences. The drug utilization studies are to promote rational $\&$ appropriate use of drugs at lowest possible cost $\&$ effective therapeutic dose .WHO has recommended indicators which acts as standard and reference for conducting and planning drug utilization studies.

Aim and Objectives: The study was aimed to evaluate the drug utilization pattern in general medicine out-patient department in tertiary care settings

Methods: It is a Hospital based, Prospective, Cross-sectional and Observational study with sample sizes of $(\mathrm{N}=$ 196) out patients from General medicine department

Results: Out of 196 patients majority of them were females accounting for 104(52.8\%) of age group (51-60).Of those 196 enrolled (30.61\%) had 4 drugs prescribed .With $85.4 \%$ of the total drugs of the study population were found to be tablet dosage forms.(63.77\%) of prescriptions contain antibiotics and (53.57\%) multivitamins in highest number.

Conclusion: This study concluded the need for rationalizing the prescribing patterns according to established standards by WHO core indicators. The areas of concern are polypharmacy, Overuse of antibiotics and multivitamins. The encouraging findings were optimal usage of proton pump inhibitors, parenteral dosage forms and free government supplies while compared with other studies conducted in tertiary setup. The spectrum of healthcare system should be broadened to include clinical pharmacists whose role should prioritize in safety, efficacy \& cost effective drug treatment.

KEYWORDS: Drug utilization research, Prospective, Essential Drug List, rational prescribing patterns.

\section{Corresponding Authors: Sushma Muchukota E-mail: sushma.banthi@gmail.com}

Indian Research Journal of Pharmacy and Science; 25(2020)2177-2183; Journal Home Page: https://www.irjps.in DOI: $10.21276 /$ irjps.2020.7.2.10 


\section{INTRODUCTION:}

Drug utilization research is defined as "marketing, distribution, prescription and use of drugs in a society, with special emphasis on the resulting medical, social and economic consequences" WHO (World Health Organization). Rational use of drug needs, that patients take medication appropriate to their clinical needs, in dose that meet their own individual requirements for the adequate period and the lowest cost to them and their community ${ }^{1}$. Irrational use of drugs and Poor management leads to prolonged suffering, morbidity, mortality, complications and loss of confidence in the health care system ${ }^{2}$. There is always a variation in drug utilization among various countries and even among health institutions within a country and sometimes within the same institute at different point of time probably because of changing disease trends over a period of time ${ }^{3}$. It holds a important point in the clinical practices and forms the basis for making amendments in the drug dispensing policies at local and national levels. The ultimate goal of such research is to facilitate rational drug use $e^{4}$. It helps in emerging strategies to utilize health resources in the most well-organized manner, it is mainly needed in a developing economics of India and $72 \%$ of all health care burdens is borne by the patients. ${ }^{5}$. The anatomical and therapeutic chemical (ATC) classification systems is accepted worldwide and also recommended by WHO. Uppsala Monitoring Centre (UMC) a WHO collaborating centre for classification of ADRs. Defined daily dose is average maintenance dose per day and used as a comparable unit. Prescribed daily dose (PDD) may not be equivalent to DDD. ${ }^{6,7}$ Rational prescribing of drugs is a skill, which includes proper knowledge about drugs, pharmacoeconomics, pharmacovigilance and experience is mandatory. If the drugs are overused, if underused and if misused it leads to increase occurrence of toxic reactions, therapeutic failure and Chances of development of resistant strain to antibiotics, will lead to unnecessary adverse drug effects and drug interactions. ${ }^{\mathbf{8}, 9}$ A number of studies have reported drug usage patterns in different health care sectors in India. ${ }^{\mathbf{1 0}}$

\section{METHODOLOGY:}

Study sample: The sample size collected in the present study is [ $\mathrm{N}=196$ Patients.]

Study Design: It is A Hospital-based, Prospective, cross-sectional and observational study. Study Period: The present study was conducted for a period of 6 months from August 2019 to January 2020.

Study site: The present study was conducted in ESI Hospital, Indira Nagar, Bangalore.

Study Criteria:

Inclusion criteria:

Patients of age group 11-80 years.

All out patient general department who were willing to participate in the study

\section{Exclusion criteria:}

The patients who are not willing to participate were excluded.

In patients are excluded.

Patients other than General medicine department are excluded.

\section{SOURCE OF DATA:}

\section{Method of collection of data:}

All the patients satisfying the inclusion criteria were selected after explaining the study to the subjects then included in the study. Tool of data collection Structured interviewing questionnaire was designed to collect data.

\section{Statistical tools:}

Data were collected from the patient's chart and was subjected to analyze by performing descriptive statistics. The obtained data tabulated and analysed in terms of objectives of the study, by using inferential and descriptive statistics.

\section{RESULTS:}

A Total of 196 patients were considered in the present study. Out of which 92 (47.17\%) were males and 104(52.8\%) were females. 
Table:1- Distribution based on gender Total sample size $(\mathrm{N}=196)$

\begin{tabular}{|c|c|c|}
\hline Gender & No. of Patients & Percentage \\
\hline Male & 92 & $47.17 \%$ \\
\hline Female & 104 & $52.8 \%$ \\
\hline
\end{tabular}

The age distribution with gender of patients enrolled in the present study revealed that most of the patients were from 51- 60 years age group. As shown in ( Table:2)

Table: 2 Distribution based on age groups

\begin{tabular}{|c|c|c|c|}
\hline Age group & No: of male patients & No; of female patients & Total \\
\hline $11-20$ & $\mathbf{6}$ & $\mathbf{9}$ & $\mathbf{1 5}$ \\
\hline $21-30$ & $\mathbf{1 2}$ & $\mathbf{1 3}$ & $\mathbf{2 5}$ \\
\hline $31-40$ & $\mathbf{1 4}$ & $\mathbf{1 7}$ & $\mathbf{3 1}$ \\
\hline $41-50$ & $\mathbf{2 0}$ & $\mathbf{2 3}$ & $\mathbf{4 3}$ \\
\hline $51-60$ & $\mathbf{1 8}$ & $\mathbf{2 7}$ & 45 \\
\hline $61-70$ & $\mathbf{1 5}$ & $\mathbf{1 2}$ & $\mathbf{2 7}$ \\
\hline $71-80$ & $\mathbf{7}$ & $\mathbf{3}$ & $\mathbf{1 0}$ \\
\hline
\end{tabular}

The number of drugs per prescription were listed in the below (Table3). The results revealed that $30.61 \%$ of the total prescriptions of the study population contained four drugs per prescription

Table 3: Number of drugs prescribed per patient

\begin{tabular}{|c|c|c|}
\hline Prescription containing no of drugs & Frequency & Percentage \\
\hline One & 7 & $3.57 \%$ \\
\hline Two & 13 & $6.63 \%$ \\
\hline Three & 51 & $26.02 \%$ \\
\hline Four & 60 & $30.61 \%$ \\
\hline Five & 37 & $18.87 \%$ \\
\hline Six & 9 & $4.59 \%$ \\
\hline Seven & 5 & $2.55 \%$ \\
\hline Eight & 7 & $3.57 \%$ \\
\hline Nine & 4 & $2.04 \%$ \\
\hline Ten & 3 & $1.53 \%$ \\
\hline
\end{tabular}


The dosage forms were listed in the (Table 4). The results revealed that $85.4 \%$ of the total drugs of the study population were found to be tablet dosage forms.

Table 4: Distribution based on dosage forms

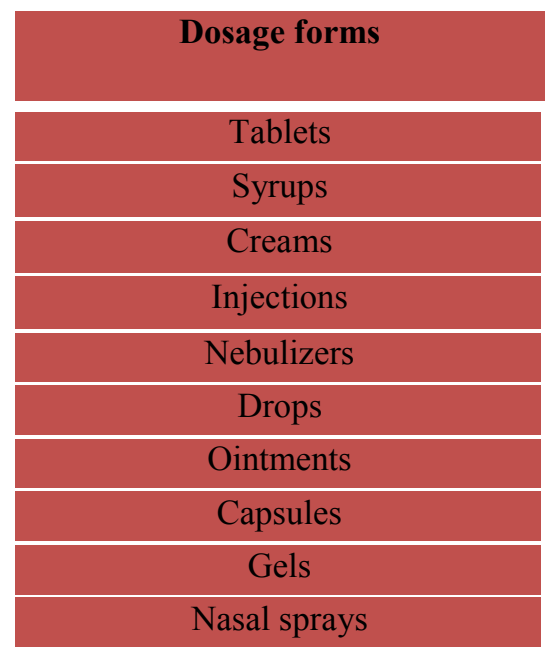

The results revealed that $(63.77 \%)$ of the prescriptions contain antibiotics and (53.57\%)

\begin{tabular}{|c|c|}
\hline No; of drugs & Percentage \\
\hline 702 & $85.4 \%$ \\
\hline 73 & $8.8 \%$ \\
\hline 3 & $0.36 \%$ \\
\hline 18 & $2.189 \%$ \\
\hline 5 & $0.608 \%$ \\
\hline 2 & $0.24 \%$ \\
\hline 7 & $0.85 \%$ \\
\hline 9 & $1.09 \%$ \\
\hline 2 & $0.24 \%$ \\
\hline 1 & $0.12 \%$ \\
\hline
\end{tabular}

multivitamins in highest number in the given study population

Table 5: Distribution based on category of drugs

\begin{tabular}{|c|c|c|}
\hline Category of Drug & No of drugs & Percentage \\
\hline Antibiotics & 125 & $63.77 \%$ \\
\hline Anti- histamines & 63 & $32.14 \%$ \\
\hline Antipyretics & 60 & $30.61 \%$ \\
\hline Multivitamins & 105 & $53.57 \%$ \\
\hline Bronchodilators & 24 & $12.24 \%$ \\
\hline Anti-emetics & 17 & $8.67 \%$ \\
\hline Analgesics & 48 & $24.48 \%$ \\
\hline NSAIDS & 49 & $25 \%$ \\
\hline Anti-hypertensives & 56 & $28.57 \%$ \\
\hline Antidiabetics & 92 & $46.93 \%$ \\
\hline Anti-thyroid & 34 & $17.34 \%$ \\
\hline PPIs & 75 & $38.26 \%$ \\
\hline Laxatives & 25 & $12.75 \%$ \\
\hline Anticonvulsants & 17 & $8.67 \%$ \\
\hline Antidiarrheal & 32 & $16.32 \%$ \\
\hline
\end{tabular}


Analysis of prescriptions in light of WHO prescribing indications:

A total of 196 prescriptions were collected randomly analyzed. A total of 822 drugs were prescribed, average number of drugs per encounter were 4.19 drugs prescribed from essential drugs list (WHO) accounted for about (34.06\%) of total prescribed drug. Total numbers of antibiotics prescribed were 125. Percentage of encounter with an antibiotic prescribed was $63.7 \%$. Percentage of encounters with injections prescribed were $9.18 \%$ as listed in (Table6).

\section{Table 6: Percentage of encounters}

\begin{tabular}{|c|c|}
\hline Parameters & Observed values \\
\hline Total no of prescriptions analyzed & 196 \\
\hline Total no of drugs prescribed & 822 \\
\hline Average no of drugs per encounter & 4.19 \\
\hline Total no of antibiotics prescribed & 125 \\
\hline Percentage of encounters with an antibiotic prescribed & $63.7 \%$ \\
\hline Percentage of encounters with injection prescriptions & $9.18 \%$ \\
\hline
\end{tabular}

\section{DISCUSSION:}

Drug utilization studies are conducted to monitor and evaluate prescribing pattern. They also suggest modification and improvement in prescribing practices and promote rational prescribing practices. Rational prescribing optimizes benefits and safety, and maximizes utilization of resources. Present study was conducted to describe and evaluate pattern of drug utilization by application of WHO core indicators, which are highly standardized and recommended. ${ }^{11}$

The number of drugs per prescriptions were analyzed the results revealed that $30.61 \%$ of the total prescriptions of the study population contained four drug per encounter, indicating polypharmacy .With the least fraction of enrolled population containing 1 ( $3.57 \%$ ) drug per encounter. Among the dosage forms drops, syrups, tablets, injections, capsules, ointments, gels, nasal sprays, creams, nebulizers. ${ }^{12}$ Tablets have been highly prescribed $85.4 \%$. The most commonly prescribed drug categories were found to be antibiotics (64.10\%), multivitamins (53.57\%)and anti-diabetics $46.93 \%$. This shows that prescribers tend to prescribe antibiotics, multivitamins and antidiabetics commonly.Drugs prescribed from essential drug list accounted for about $34.06 \%$ of total drugs prescribed. Essential drugs offer a cost effective solution to healthy problems and its availability should be ensured at all times, in appropriate dosage forms and better quality. Due to lack of awareness in developing countries like India there is a need to gear up, which shows a low score of the drugs prescribed from EDL. The total number of antibiotics prescribed were 125 which accounted for about $63.7 \%$ of total prescriptions encountered. Whereas the core indicators of WHO states prescribing antibiotics in range of $15-25 \%$ is more appreciable and accepted ${ }^{13}$. To wade off the increasing risks \& cases of Antimicrobial resistance, due to overuse or abuse of Antibiotics the prescribers should prescribe it cautiously. The percentage of encounters with injections prescribed was $9.18 \%$. Although the use of injections serve advantage of delivering drug at fastest pace and greater bioavailability when compared to oral route, it is also accompanied with increased risk of tissue toxicities, local irritation and difficulties of correcting errors as the drug input cannot be terminated once injected ${ }^{14}$. Our study reveals quite a satisfactory range of injections prescribed (9.18) in comparison to recommended 
standards of WHO less than $10 \%$ prescriptions should include one or more injections.

\section{CONCLUSION:}

This study is dedicated to the drug utilization patterns in general outpatient department. It has helped to identify irrational prescribing patterns. The areas of concern reported in this study were polypharmacy, increased use of antibiotics. The encouraging findings from this study were optimal usage of proton pump inhibitors, parenteral dosage forms and free government supplies while compared with other studies conducted in tertiary setup. There is a need for more such studies in other departments including larger number of patients. In this study although the cost of treatment is borne by government, rational prescribing patterns should be encouraged. The spectrum of Healthcare system should be broadened to include Clinical pharmacists, whose role should prioritize in safety, efficacy \& cost effective drug treatment.

\section{LIMITATIONS OF THE STUDY:}

Relatively lesser number of patients were enrolled into the study. As the study considered outpatients of general department, the patient compliance cannot be monitored .The study can be expanded in future by including inventories maintained by pharmacist reflecting on availability of essential drugs which would encourage the pattern of prescribing drugs from EDL. There are lesser studies available, frequent and long duration studies are required. The studies involving prescribing patterns in special populations like pediatrics, pregnant, lactating women \&geriatrics can be taken up .A comparative study to analyze prescribing patterns in both government \& private sector can also be suggested. Due to free supply of medicines our study couldn't make calculations of cost of drugs per prescription.

\section{ACKNOWLEDGMENT:}

We are grateful to Almighty for giving us the strength to successfully conduct our work. We express our sincere thanks To Dr. RINKU MATHAPPAN, Principal of Gautham College of Pharmacy, we would like to appreciate and thank all the participants that participated in the research.

\section{REFERENCES:}

1. WHO policy perspectives in medicines. Promoting rational use of medicines: World Health Organization.2002. Available at:http://www/who.int/medicines/publication s/policyperspectives/ppm05en.pdf. Accessed 19 July 2018

2. Foster S. Supply and use of essential drugs in sub-Saharan Africa: some issues and possible solutions. Social Sci Med. 1991 Jan 1;32(11):1201-18.

3. U. Bergman, I. Christenson, B. Jansson, and B. E. Wiholm, “Auditing hospital drug utilisation by means of defined daily doses per bed-day. A methodological study," European Journal of Clinical Pharmacology, vol. 17, no. 3, pp. 183-187, 1980

4. G.Parthasarathi, Karin Nyfort-Hanse, Milap C Nahata. A Textbook of Clinical Pharmacy Practice. Second edition 2012.

5. PD. Sachdeva. Drug utilization studies scope and future perspectives .Ijpbr,2010;1(1);11-17.

6. Bergman U, Elmes P, Halse M, Halvorsen $\mathrm{T}$, Hood $\mathrm{H}$, Lunde $\mathrm{PK}$, et al. The measurement of drug consumption- Drugs for diabetes in Northern Ireland, Norway and Sweden. Eur J ClinPharmacol 1975; 8:83-89.

7. Bergman U., Gimsson A., Wahba A., Westerholm B., editors. (eds). (1979). Studies in Drug Utilization - Methods and Applications. Copenhagen: World Health Organization Regional Publications.

8. Bergman U, Elmes P, Halse M, Halvorsen $\mathrm{T}$, Hood H, Lunde $\mathrm{PK}$, et al. The measurement of drug consumption- Drugs for diabetes in Northern Ireland, Norway and Sweden. Eur J ClinPharmacol 1975; 8:83-89.

9. Bergman U., Gimsson A., Wahba A., Westerholm B., editors. (eds). (1979). Studies in Drug Utilization - Methods and Applications. Copenhagen: World Health Organization Regional Publications.

10. Barot PA, Malhotra SD, Rana DA, Patel VJ, Patel KP. Drug utilization in emergency 
medicine department at a tertiary care teaching hospital: a prospective study. Journal of Basic and Clinical Pharmacy. 2013;4: 78-81.

11. ISSN No: 2231-6876 Chaudhary PK, Maurya AK, Jain A, Pathak A, Sharma N. Drug utilization pattern in medicine department in a tertiary care teaching hospital in Uttar Pradesh. Indo Am Journal of Pharmaceutical Research, 2015.

12. Meher BR, Mukharjee D, Udayshankar. A study on antibiotic utilization pattern in a general medicine ward of a tertiary care teaching hospital. Journal of Chem and Pharma Res, 2014; 6(7):1847-9.
13. Srishyla MV, Krishnamurthy M, Nagarani MA, Clare SM, Andrade C, Venkataraman BV. Prescription audit in an Indian hospital setting using the DDD (Defined Daily Dose) concept. Indian J Pharmacol.1994; 26:2328.

14. Kaur S, Rajagopalan S, Kaur N, Shafiq N, Bhalla A, Pandhi P, and Malhotra S. Drug utilization study in medical emergency unit of a tertiary care hospital in North India. Hindawi Publishing Corporation, Emergency Medicine International, 2014; 15. 